Voix et Images

volxetimages

\title{
Best-sellers : De l'amour, des crimes et du suspense...
}

\section{Marcelle Fontaine}

Volume 12, numéro 1 (34), automne 1986

Québec-Amérique latine

URI : https://id.erudit.org/iderudit/200618ar

DOI : https://doi.org/10.7202/200618ar

Aller au sommaire du numéro

\section{Éditeur(s)}

Université du Québec à Montréal

\section{ISSN}

0318-9201 (imprimé)

1705-933X (numérique)

Découvrir la revue

\section{Citer cet article}

Fontaine, M. (1986). Best-sellers : De l'amour, des crimes et du suspense... Voix et Images, 12(1), 152-154. https://doi.org/10.7202/200618ar d'utilisation que vous pouvez consulter en ligne.

https://apropos.erudit.org/fr/usagers/politique-dutilisation/ 


\title{
Best-sellers: De l'amour, des crimes et du suspense...
}

\author{
par Marcelle Fontaine, Université Sainte-Anne
}

De l'amour, des crimes et du suspense...

Mal aimés? Enfants illégitimes de la littérature? De moins en moins. Les best-sellers, romans policiers et romans à suspense font maintenant partie de la littérature. En témoignent les critiques qui accompagnent leur parution et l'intégration de ces genres parallèles au corpus universitaire. Selon une tradition somme toute élitiste, les critiques et les universitaires réservaient leur encre pour des romans jugés plus nobles, romans qui doivent désormais partager le terrain littéraire avec une production plus populaire. Bien sûr, les livres à succès n'ont pas toujours droit de cité. Mais quand ces romans apparaissent comme les rejetons d'auteurs québécois, il devient de plus en plus difficile de les passer sous silence. Qu'on le veuille ou non, nos producteurs s'adonnent de plus en plus à une écriture dite commerciale. Certains se voient même consacrés par le biais de prix littéraires. Ainsi en est-il du roman d'Alexander LaHaye et d'Hélène Trudeau, qui s'est mérité le prix Esso 85.

Opération Bernard II ${ }^{1}$ présente, du moins extérieurement, toutes les caractéristiques du livre à succès, format $16 / 24$, fort volume de 500 pages, couverture illustrée, couleurs voyantes, etc. D'ailleurs, l'ouvrage n'est pas sans rappeler le Cinquième cavalier, roman classé parmi les meilleurs vendeurs au cours de l'année 1980. Dans les deux cas, l'intrigue repose sur la mise en place et l'exécution d'une entreprise de chantage dirigée contre la Maison blanche. Complot qui engendre l'émoi et la panique dans les plus hautes sphères des États-Unis. S'affrontent alors le bien et le mal et la lutte se termine par la victoire des maître-chanteurs de l'Opération Bernard II. À cet accroc aux règles du best-seller où les bons sont toujours gagnants, s'ajoutent des maîtres-chanteurs qui se révèlent fort sympathiques. Aussi le lecteur, partagé entre les "bons bons» et les «bons méchants", ne sait plus trop à qui s'identifier. Bref, les auteurs parviennent à créer une agréable confusion entre les premiers et les seconds.

Les personnages captivants de prime abord, surtout celui de Jonathan Forbes, ancien agent de la C.I.A. et instigateur du complot, perdent malheureusement tout relief au profit de la dimension stratégique de l'opération. I] semble que les auteurs aient voulu montrer à tout prix, et même au risque d'ennuyer le lecteur, la perfection de l'entreprise dans ses moindres rouages. Pareil souci nuit au suspense. En fait, l'intrigue est noyée dans une mer de détails stratégiques, ce qui rend parfois la lecture difficile. Aussi, je doute qu'Opération Bernard II, obtienne un succès de librairie comparable à celui qu'a connu le Cinquième cavalier.

Le premier roman de Léon-Gérald Ferland me semble davantage réunir les qualités susceptibles d'attirer le grand public. Ouvrage de quelque deux cents pages, Meurtre Éclair, ${ }^{2}$ s'inscrit dans la lignée du roman policier. Un 
meurtre est commis à la prison commune de Montréal et Vendale, l'un des détenus, en est le présumé coupable. Commence alors le procès de l'accusé, vaillamment défendu par son avocate Christine Ferraud. Le témoignage des codétenus et supposés amis de Ti-Coq (Vendale), loin de l'innocenter, l'incrimine davantage. Tous les dessous souvent sordides de la vie en prison surgissent sous l'œil impassible de Le Pêne, juge désespéré par la bêtise humaine et davantage préoccupé de la bonne marche du procès. L'intrigue est bien menée et les personnages demeurent attachants bien que grossièrement esquissés. En dépit de cet aspect, le roman demeure, dans le genre, tout à fait intéressant.

Si L. Ferland construit son roman à partir d'un crime, c'est sur une

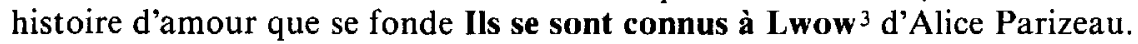
En toile de fond se joue la dramatique histoire du peuple polonais pendant la deuxième guerre mondiale. Lala et Bronek, tous deux natifs de Lwow, s'aiment et désirent s'épouser. La guerre éclate, ils sont séparés et ne se retrouvent que bien des années plus tard. Derrière ce scénario classique et maintes fois exploité, l'auteure retrace la malheureuse trajectoire des Polonais. D'une voix à la fois compatissante et indignée, Alice Parizeau expose non seulement les souffrances de ce peuple, mais aussi la politique d'abandon des alliés à leur égard.

La deuxième guerre mondiale et ses atrocités a largement nourri le roman. A. Parizeau, en mettant en scène un peuple habituellement laissé pour compte dans ce genre de récit, donne une perspective différente aux événements de 1939-44. Habitué aux péripéties spectaculaires d'un héros américain ou juif aux prises avec les Allemands, le lecteur se retrouve dans Ils se sont connus à Lwow, avec des personnages de dimension humaine. Leurs actions ne participent pas de l'extraordinaire. Elles témoignent plutôt de la modestie des moyens dont disposent certains peuples lorsqu'ils sont mêlés à un conflit entre les grandes puissances. Pour ces héros, contrairement aux modèles habituels, la guerre se solde par l'exil et la défaite.

Si quelques auteurs québécois se consacrent maintenant à des genres littéraires plus commerciaux, on constate par ailleurs une transgression de certaines règles du genre. Les romans de L. Leblanc et J.R. Sansfaçon Pop Corn $^{4}$ et Loft Story ${ }^{5}$ illustrent tout à fait cette démarche. Même si ces deux ouvrages empruntent aux livres à succès son enveloppe extérieure, le contenu déroge à la facture habituelle. Jean-Robert Sansfaçon parle bien d'amour dans Loft Story, mais d'un amour dont la représentation se situe à des milles du drame invraisemblable et du "happy-end" à mouchoir. Il s'agit plutôt d'une transcription fidèle de la désillusion amoureuse vécue par ceux qui, dans les années soixante, ont jeté par dessus bord normes et vieux modèles pour tout réinventer. Refusant les anciennes structures familiales et incapables d'en créer de nouvelles vraiment satisfaisantes, les héros du roman se promènent d'un échec amoureux à l'autre.

Francis Langevin, âgé d'environ trente ans, vit modestement de son métier de graphiste. Côté amour, il se trouve écartelé entre son ex-épouse Geneviève, peintre et femme excessive et Maude, sa nouvelle maîtresse, qui 
est chanteuse-rock. Ces différentes carrières, loin d'apporter le confort financier et la renommée, renvoient chacun des personnages à des succès aléatoires et à la peur constante de l'échec.

Ce roman reproduit les états d'âme, les déceptions et les peurs de toute une génération qui aborde la trentaine d'un œil triste et inquiet. Le style soutenu de Loft Story en facilite la lecture. Mais ce roman, par un ancrage référentiel trop marqué, semble ne pas avoir de vie propre: de ce fait, il n'atteint pas vraiment le lecteur.

Si l'imaginaire fait défaut dans Loft Story, les pirouettes de Louise Leblanc dans l'invraisemblable et dans la bizarrerie font tout le charme de son deuxième roman Pop Corn. Les premières pages peuvent rebuter l'amateur d'une certaine linéarité. Ça va vite et dans tous les sens. À cet égard, le titre est judicieusement choisi, puisqu'il métaphorise parfaitement le style du roman. Ça éclate, ça bouge et c'est léger. On croirait lire le texte d'une bande dessinée. Les personnages sont caricaturés, à peine crédibles et les événements rocamboleques.

Kaven O'Brien, québécois dans la cinquantaine qui se définit comme un raté, retrouve sur le toit de sa vieille Cherokee une femme ensanglantée et inconsciente. Elle ressemble étrangement à Pop Corn, vedette américaine des années soixante. S'amorce alors une enquête qui doit servir à l'élaboration de la biographie de la star. Recherches qui font surgir E.T., Marilyn Monroe, James Dean, Leonard Cohen, Tenessee Williams et j'en passe. À cet imbroglio s'ajoute une querelle entre l'auteure et Kaven qui, dit-elle, lui cache certains renseignements. Elle qui doit défendre les intérêts du lecteur menace de le faire disparaître. Les intrusions de cette dernière, loin de briser le rythme du récit, font sourire et amusent. (Elle ira même fouiller dans la poubelle pour récupérer un bout de papier que Kaven y a jeté sans en divulguer le contenu au lecteur.) Pareil procédé démontre clairement la distance prise par Louise Leblanc par rapport aux attentes du grand public en matière de clarté, d'une certaine vraisemblance et du respect des structures narratives.

Même si le volume des romans augmente, que les jaquettes sont désormais illustrées dans des couleurs voyantes et qu'on annonce à la quatrième page couverture amour et crime, il ne faut pas s'y méprendre. Bien sûr les thèmes utilisés ont fait leurs preuves sur le marché, mais le traitement diffère. Ce remaniement ébranle les clichés et donne des personnages beaucoup moins stéréotypés. Les méchants se confondent avec les bons, les héros engraissent et ont le cafard, les self-made-men vivotent et qui plus est, l'amour bat de l'aile. Bref, on investit dans la grande production mais, semble-t-il, avec un souci de distinction. Entreprise qui risque fort de décevoir les amateurs de best-sellers, formule américaine.

1. Alexander LaHaye, Hélène Trudeau, l'Opération Bernard II. Montréal, Pierre Tisseyre, 1985, $512 \mathrm{p}$.

2. Léon-Gérald Ferland, Meurtre Éclair, Montréal, Leméac, 1985, $189 \mathrm{p}$.

3. Alice Parizeau, Ils se sont connus à Lwow, Montréal, Pierre Tisseyre, 1985, 363 p.

4. Jean-Robert Sansfaçon, Loft Story, Montréal, Quinze, 1986, $219 \mathrm{p}$.

5. Louise Leblanc, Pop Corn, Montréal, Quinze, 1986, 289 p. 